\title{
Thermal stresses and cracking in absorptive solar glazing
}

\author{
H. Chowdhury and M.B. Cortie* \\ University of Technology Sydney, PO Box 123, Broadway, NSW 2007, Australia
}

\begin{abstract}
The emerging popularity of absorptive, as opposed to reflective, solar glazing coatings on windows has generated renewed interest in thermally-induced cracking of glass structures. Here we analyse the stresses on glass coated with absorptive solar glazing films caused by uneven solar illumination. It is shown that the occasionally reported brittle fracture of such structures can be readily explained as being the result of differential thermal expansion of the glass. The magnitude of the effect is linearly proportional to the Shading Coefficient of the glass and is also influenced by the manner in which the glass is supported.
\end{abstract}

Keywords: thermal stress, solar glazing, glass, absorptive coatings, fracture

\section{Introduction}

Various coatings and tints applied to window glass have the ability to reflect or absorb infrared radiation incident from the sun and thereby reduce heat load in the interior of a building. However, in the case of glass coated with absorptive materials, the surface of the glass becomes hot as a result. This increased temperature will cause thermal expansion, which if uneven or if not matched by expansion of the window frame, will generate stresses within the pane. The risk of breakage of the glass depends on several variables, including stress, edge strength, area under stress, time duration of the stress, and presence of edge defects. Intermittent reports of coated glass panes that had unexpectedly fractured during service prompted the authors to investigate the magnitude of the thermal stresses developed in glass coated with infrared absorbing materials, and the relationship of these stresses to uneven illumination by sunlight. The stresses in two simplified geometries were modelled using Finite Element Analysis (FEA). These calculations were not intended to quantitatively replicate the stresses in any real structures, but

\footnotetext{
* Corresponding author. Tel.+61-2-9514-2208, email address : $\underline{\text { michael.cortie@uts.edu.au }}$
} 
were rather carried out in order to qualitatively illustrate the phenomena and trends that occur in coated glass panes subjected to solar illumination.

\section{Experimental}

Comparative data was first obtained for a variety of absorptive glass types using panes measuring $0.25 \times 0.25 \mathrm{~m}$ subjected to an array of incandescent lights. The distance between the light and the glass was adjusted to give a relatively uniform irradiance of $500 \mathrm{~W} / \mathrm{m}^{2}$. This figure is representative of a vertical east- or west-facing window in Sydney or Houston during March and September. The radiation from the lamps was measured with a thermopile detector (PMA 2143, from Solar Light Co, USA), while the temperatures of the inner and outer surfaces of the glass sheet were monitored using thermocouples as well as a surface thermometer. Detailed results of the experiment and further information on the properties of the glasses used have been published elsewhere [1] but are summarized here in Table 1.

Samples 'XL121', 'PNTHR50' and 'Aktiv' are absorptive in nature, 'VKOOL 40' is reflective, and 'Au1' and 'Au-2' are experimental coatings based on gold nanoparticles. 'XL121' was the material used in the glass panel that fractured.

The finite element package used was 'Ansys' by Ansys Incorporated, of USA. The thermal load was applied as a user-defined rate of heat generation on the lower half of the glass panel only. The magnitude of heat generation can be readily parameterized from the Shading Coefficient of the glass. A two dimensional model was used for the thermal part of the analysis. Only the steady-state thermal and load solutions were considered. Under real life conditions the behaviour of the glass would be slightly non-linear because of the dependence of its elastic modulus and other physical properties on temperature. However, since the state of stress in this elastic system is dominated by the value of Youngs modulus, which does not vary by more than $\sim 1 \mathrm{GPa} / 100 \mathrm{~K}[2]$, giving a variation of only $0.4 \%$ over the temperature range $\left(20\right.$ to $\left.50^{\circ} \mathrm{C}\right)$ of interest, we have adopted a quasi-linear approach, using the material properties at $20^{\circ} \mathrm{C}$ as our input parameters. The results presented in this paper assume a condition of biaxial, plane stress in the glass. The reason is that initial FEA calculations of the three-dimensional geometry showed that the stress in the $z$-direction was unimportant for the heat loads and pane sizes used here. This is due to the reasonably good heat conductivity of glass. However, this generalization would not necessarily apply to heat loads of greater than $500 \mathrm{~W} / \mathrm{m}^{2}$, to laminated glass structures, or to glass thicker than the standard $4 \mathrm{~mm}$. 
Implementation of the FEA requires values for diverse other material parameters [3,4], Table 2, as well as estimates for the heat transfer coefficient, $h$, defined by

$$
Q_{\text {conv }}=\left(T_{s}-T_{\text {air }}\right) * A * h
$$

Values of $h$ can be estimated for each value of face temperature using a sequence of empirical relationships [5] involving the Nusselt number, the thermal conductivity of air and the height of the glass pane. Values of $h$ were calculated for the interior and exterior surfaces of the glass using the measured values of surface temperature, and used in the subsequent finite element analyses.

Finally, the actual FEA itself was carried out in two steps. First, the meshed model was created, the preference set to 'thermal', the heat transfer problem solved, and the results saved to disk. Next the heat transfer boundary conditions and thermal loads were removed from the mesh, the preference changed to 'structural', the element type switched from 'thermal' to 'structural', the calculated temperature distribution re-imposed, and the displacements due to the calculated temperatures applied.

A particular case study was made of the thermally-induced stress in a door-shaped glass pane subjected to partial solar illumination. This was selected after discussions with a contractor, who provided an example and information on such a structure that had cracked when it had been illuminated by morning sunlight. The solar screening functionality of the pane had been achieved by means of a polymer film containing a substance that preferentially absorbed infrared radiation. The pane simulated measured 0.91 by $2.53 \mathrm{~m}$ and was modelled with its bottom half in full sunlight and its top half at an initial temperature of $293 \mathrm{~K}\left(20^{\circ} \mathrm{C}\right)$. A heat load of up to $300 \mathrm{~W} / \mathrm{m}^{2}$ was applied to the bottom half of the panel, and the top and bottom edges of it were considered to be infinite heat sinks at 293K. Two different structural scenarios were considered. In the first the panel was fixed at the top and bottom to an infinitely stiff structure at $293 \mathrm{~K}$, and in the second only the bottom edge was pinned.

\section{Results}

\subsection{Temperature vs absorbed heat}

The rise of the surface temperature of the glass due to the presence of an absorptive coating leads to convective heat transfer to the external and internal environments, according to Equ. (1). The relative proportions of heat convected inwards or outwards depends on the air temperatures and velocities of the corresponding internal and external environments. In general, over half the heat load 
generated by the coatings is shed into the exterior environment by convection, and somewhat less than half into the interior [1]. A small proportion of the absorbed energy is re-emitted as radiation but this effect is small for the low values of $T$ and $\Delta T$ involved here. Various surface temperatures $\left(T_{s}\right)$ may be assumed in Equ. (1), and used to give corresponding values of $h$. Finally, the total heat convected from front and back surfaces can then be calculated, which will be approximately equal to the total heat absorbed by the glass pane (Fig.1). The resulting graph can be used to determine the actual amount of heat absorbed by a surface when its surface temperature is known and vice versa, provided that the air temperature is about $20^{\circ} \mathrm{C}$.

\subsection{Thermal stresses}

The thermal expansion of the heated glass generated significant stresses. These were compressive in nature, along both vertical and horizontal edges when it was pinned at top and bottom, due obviously to fact that movement of the top edge of the pane could not take place. However, besides some possible buckling, this situation is not likely to cause failure since edge defects in the glass will not propagate (see Discussion) under compressive loads. The tendency towards buckling would be associated with the magnitude of $\sigma_{y}$, which is a maximum at a point about one third of the height of the panel, Figure 2.

In contrast, significant tensile stresses were generated in the second scenario, where the glass panel was fixed only at its base. Figure 3 a shows the principal stresses, $\sigma_{1}$, calculated for a heat load of $200 \mathrm{~W} / \mathrm{m}^{2}$, as an example for this type of constraint. There is obviously a concentration of tensile stress along the flanks of the glass at position A, and along its base. The tensile stress $\sigma_{1}$ at position $\mathrm{A}$ is oriented in the ydirection, and will therefore tend to cause breakage, while the maximum in stress $\sigma_{\mathrm{x}}$, along the base is actually at position B. This is because the principle stress, $\sigma_{1}$, elsewhere along the bottom edge is rotated out of the x-direction. The variation in $\sigma_{\mathrm{y}}$ at position $\mathrm{A}$, and $\sigma_{\mathrm{x}}$ at position $\mathrm{B}$, is shown in Fig. $3 \mathrm{~b}$. It is evident that tensile stresses of up to $7 \mathrm{MPa}$ can act along the edges of the glass under the assumed conditions. 


\section{Discussion}

Thermally-induced stress on glass can also be estimated based on total solar absorbance of the glass and its Thermal Stress Factor, TSF. The latter is determined as the ratio between the nominal edge stress and solar load [6], where solar load can be found by multiplying the maximum solar radiation incident on the surface of the glass by the total solar absorbance of the glass (as a percentage). The magnitude of the nominal edge stress can be expressed as:

$$
\sigma_{\text {thermal }}=T S F \times S L
$$

where $\sigma_{\text {thermal }}$ is expressed in $\mathrm{kPA}$, TSF is expressed in $\mathrm{kPa} /\left(\mathrm{W} / \mathrm{m}^{2}\right)$, and SL is the solar load. TSF can be obtained from a chart, Fig.4, which has been developed based on three different support conditions for 6 mm rectangular annealed glass [6]. In Fig, 4, 'edge bite' is the width of the glass perimeter strip that is inserted inside the supporting frame.

The most unfavourable edge condition is the 'heat sink' condition which occurs when the edge bite is encased in concrete or in a thick-walled metal frame having large thermal mass. This prevents the edge of the glass from warming when the main body of the glass is exposed to solar radiation. In such a situation the edge regions of the glass remain at its overnight equilibrium temperature while the central surface exposed to solar radiation rapidly reaches a higher temperature. This condition leads to the induction of high temperature gradients, which may induce thermal breakage. The 'conventional' condition is when the glass edge is set in a thin-walled aluminium frame supported by rubber perimeter gaskets on the interior and exterior surfaces. The glass is set in the block with sufficient clearances between glass edge and metal so that a reasonable thermal expansion can be accommodated without the introduction of support induced stress. This scenario provides conservative results for typical wooden or vinyl window frames.

The magnitude of the thermal stress induced in a glass plate can therefore be estimated as a function of the solar absorption properties of the glass, the size, and the support condition. To evaluate thermally-induced edge stress in the glass we considered the case of the door-shaped glass panel, made of the 'XL121' heat absorbing glass and subjected to $500 \mathrm{~W} / \mathrm{m}^{2}$ of solar radiation. The panel was considered to be continuously supported on all four sides with a $6 \mathrm{~mm}$ edge bite, within a frame of the 'heat sink' type. Since about $48 \%$ of radiation is absorbed by this type of glass, and the TSF is equal to 32 $\mathrm{kPa} /\left(\mathrm{W} / \mathrm{m}^{2}\right)$ from Fig. 4 , the thermally induced edge stress would be $\sigma_{\text {thermal }}=32 \times 500 \times 0.48 \approx 7.7 \mathrm{MPa}$. 
This stress can be compared to an allowable thermal edge stress associated with an acceptable probability of breakage, per day, using a Probability-of-Breakage (POB) Chart [6], Fig. 5.

Figure 5 shows that, for an edge perimeter of $6.08 \mathrm{~m}$ (corresponding to the panel) and for a POB of 0.001 , the maximum allowable edge stress is $\sim 7 \mathrm{MPa}$. The induced stress in the above XL121 glazing has been estimated as $\sim 8 \mathrm{MPa}$ from Figure 5 and $\sim 6 \mathrm{MPa}$ by FEA (at position A, Fig. 3b). Therefore, there appears to be close to a 0.0001 probability-of-breakage of this structure when illuminated. Any stress concentration induced by faulty installation will further exacerbate the problem. The critical combination of stress and crack length at which fracture commences for an edge crack in glass is [7]

$$
K_{c}=1.1 \sigma \sqrt{\pi a}
$$

where $K_{\mathrm{c}}$ is the fracture toughness, which for glass may be taken as $0.7 \mathrm{MPa} \cdot \mathrm{m}^{1 / 2}[8], \sigma$ is the allowable stress in MPa and $a$ is the crack length in meters. The net effect of Equ (3) is to impose a maximum safe stress for any given crack size, Figure 6 . Therefore, the maximum edge flaw that can be tolerated in these glass doors when subjected to edge stresses of 6 to $8 \mathrm{MPa}$ is of the order of 2 to $3.5 \mathrm{~mm}$. Should any defect of this size arise in the glass due during handling, then the probability of failure is very high.

\section{Conclusions}

The thermal stress developed in partially illuminated panes of heat absorbing glass was investigated. Temperature and stress distributions in a simplified configuration were calculated with the assistance of finite element analysis and published design data. The aim of the analysis was to gain a better understanding of the response of glazed structures under radiative thermal loads. It was shown that edge stresses of $\sim 6$ to $8 \mathrm{MPa}$ can be readily generated in heat absorbing glass under some conditions of constraint and illumination. These stresses are sufficient to raise the probability of failure of a doorshaped glass panel to 0.0001 per day.

\section{Acknowledgement}

The support of AngloGold Ashanti Australia Limited, Mant Glass, Wollongong, Australia, and Dr Phuoc Huynh of University of Technology Sydney is gratefully acknowledged. 
- Short communication -

\section{References}

1. Chowdhury H, Xu X, Huynh P and Cortie MB, Radiative heat transfer across glass coated with gold nano-particles, Journal of Solar Energy Engineering(ASME), in press, publication due February 2005.

2. P.D. Warren, Pilkington Glass, UK, private communication, 8th December 2004.

3. http://www.abrisa.com/downloads/soda lime_float.pdf, accessed $21^{\text {st }}$ December 2004.

4. Incropera FP, DeWitt DP, Fundamentals of heat transfer. New York: John Wiley \& Sons, 1996.

5. Holman JP, Heat transfer. London : McGrawHill, 1992.

6. Lingnell AW, Beason L, A method of evaluation for thermal stress in monolithic annealed glass. Proc. Glass Processing Days 2003, Tamglass Ltd Oy, Tampere, Finland, 2003, p.291-293.

7. Hertzberg RW, Deformation and fracture mechanics of engineering materials. New York: Wiley,1976.

8. Ashby MF, Jones DRH, Engineering materials-an introduction to their properties and applications, Oxford :Pergamon, 1980. 
Table 1. Energy balance for a 29 watt total heat load with tungsten $2800 \mathrm{~K}$ radiation applied to a variety of glazing systems at an intensity of $500 \mathrm{~W} / \mathrm{m}^{2}$, extracted from [1].

\begin{tabular}{|c|c|c|c|c|c|c|}
\hline \multirow[t]{3}{*}{ Glass type } & \multicolumn{2}{|c|}{ Temperature ${ }^{\circ} \mathrm{C}$} & \multirow{2}{*}{$\begin{array}{l}\text { Radiation } \\
\text { transmitted }\end{array}$} & \multirow{2}{*}{$\begin{array}{l}\text { Radiation } \\
\text { reflected, }\end{array}$} & \multirow{2}{*}{$\begin{array}{l}\text { Convected } \\
\text { energy, front } \\
\text { face }\end{array}$} & \multirow{2}{*}{$\begin{array}{l}\text { Convected } \\
\text { energy, back }\end{array}$} \\
\hline & & & & & & \\
\hline & Front & Back & $\mathrm{W}$ & $\mathrm{W}$ & $\mathrm{W}$ & $\mathrm{W}$ \\
\hline $3 \mathrm{~mm}$ clear & 32 & 31 & 24.2 & 1.6 & 2.5 & 1.9 \\
\hline XL121 & 45 & 42 & 14.7 & 1.7 & 7.5 & 6.3 \\
\hline PNTHR50 & 43 & 41 & 14.1 & 2.6 & 6.4 & 5.8 \\
\hline $\mathrm{V}_{\mathrm{KOOL}} 40$ & 39 & 37 & 2.3 & 17.5 & 4.8 & 4.1 \\
\hline Aktiv & 40 & 39 & 17.2 & 1.7 & 5.4 & 5.1 \\
\hline $\mathrm{Au}-1$ & 37 & 36 & 20.0 & 2.0 & 3.8 & 3.5 \\
\hline $\mathrm{Au}-2$ & 39 & 38 & 17.2 & 2.0 & 5.8 & 4.5 \\
\hline
\end{tabular}

Table 2. Material properties used in simulation.

\begin{tabular}{llll}
\hline Properties & Symbol & Value & Units \\
\hline Thermal expansion co-efficient & $\alpha$ & $90 \times 10^{-7}$ & $/{ }^{\circ} \mathrm{C}$ \\
Modulus of elasticity (Young Modulus $\}$ & $E$ & $6.3 \times 10^{10}$ & $\mathrm{~Pa}$ \\
Poisson's ratio & $v$ & 0.22 & \\
Emissivity & $\varepsilon$ & 0.92 & \\
Density & $\rho$ & 2500 & $\mathrm{~kg} / \mathrm{m}^{3}$ \\
Thermal conductivity & $k$ & 1.4 & $\mathrm{~W} / \mathrm{m} . \mathrm{K}$ \\
Specific heat & $c_{p}$ & 750 & $\mathrm{~J} / \mathrm{kg} \cdot \mathrm{K}$ \\
\hline
\end{tabular}


- Short communication -

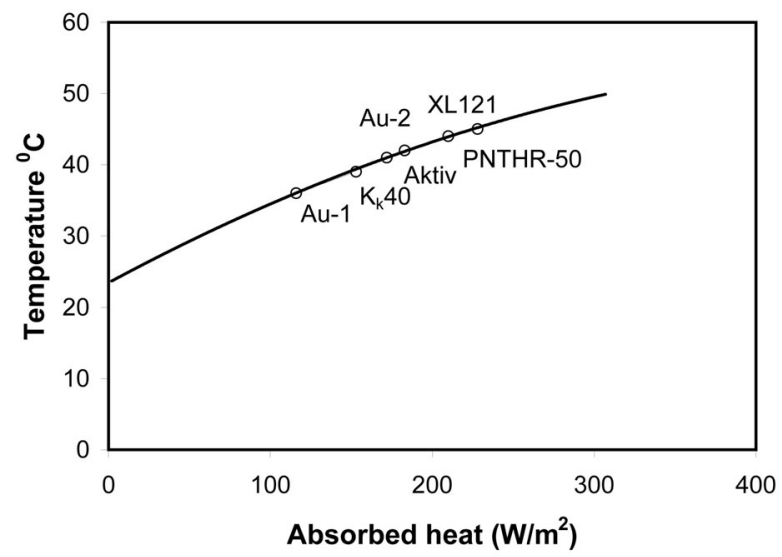

Fig. 1. Temperature of the glass surface as a function of absorbed heat, showing surface temperatures of various experimental glazing systems, under still air conditions. 


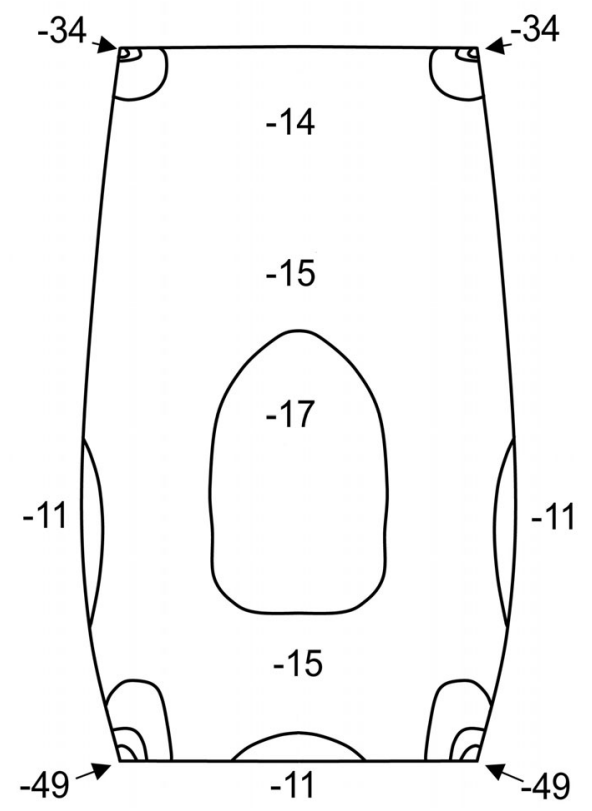

(a)

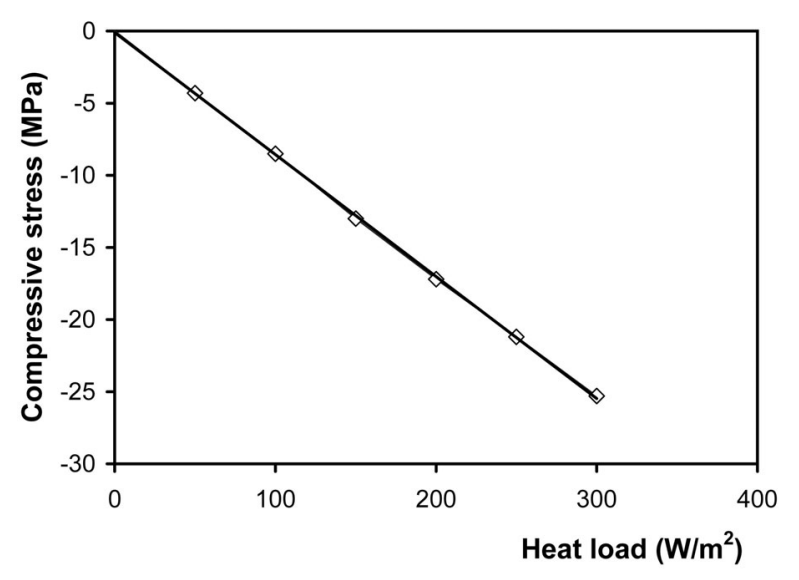

(b)

Fig. 2. Buckling stresses, $\sigma_{y}$, developed in glass panes illuminated over their bottom halves while rigidly fixed top and bottom to an infinitely stiff support, (a) distribution of $\sigma_{\mathrm{y}}$ for a heat load of $200 \mathrm{~W} / \mathrm{m}^{2}$, (b) maximum compressive stress developed in vertical centre line of glass panel, as a function of heat load. 


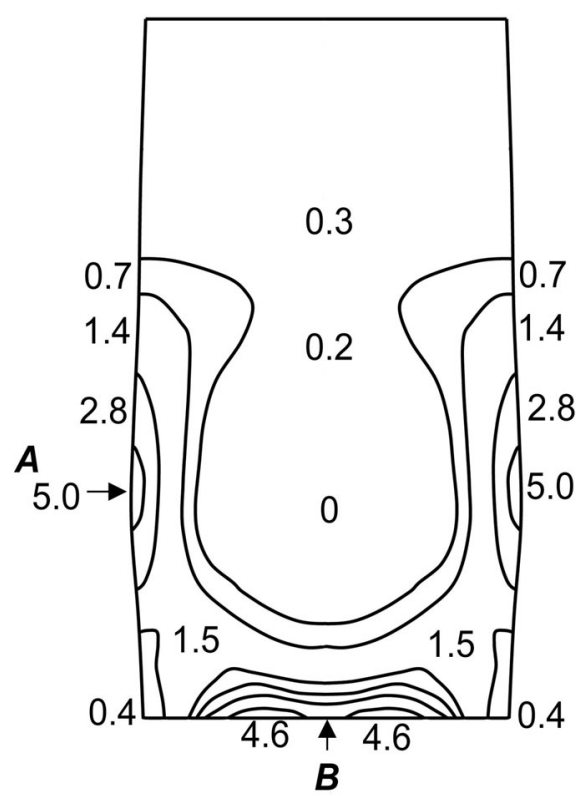

(a)

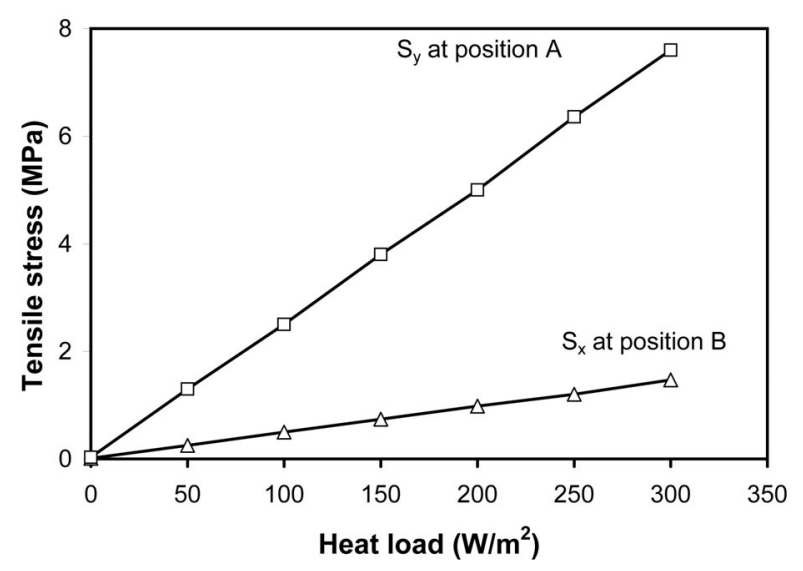

(b)

Fig. 3. Principle stresses developed in glass panes illuminated over their bottom halves while rigidly fixed only along their bottom edges, (a) distribution of principle stress when bottom half of pane is illuminated at a heat load of $200 \mathrm{~W} / \mathrm{m}^{2}$, (b) maximum tensile stresses along edges of glass panel as a function of heat load. 


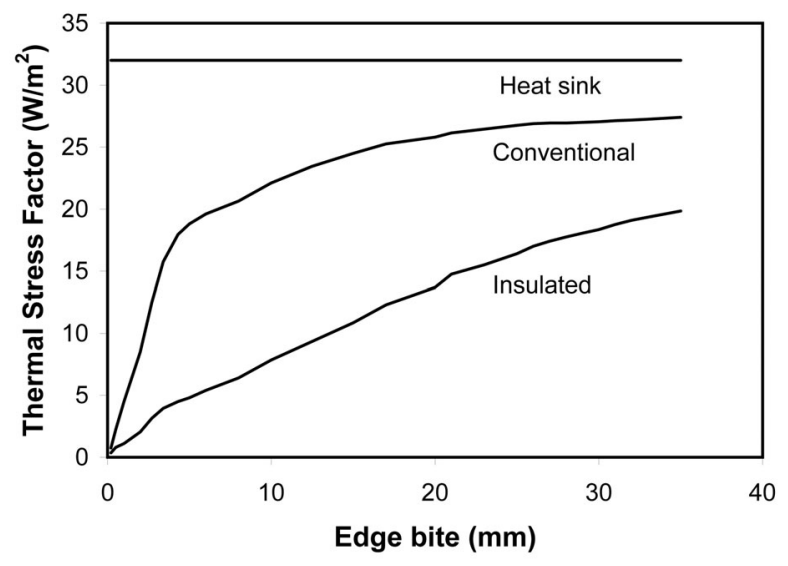

Fig.4. Thermal Stress Factor chart, redrawn from [6]

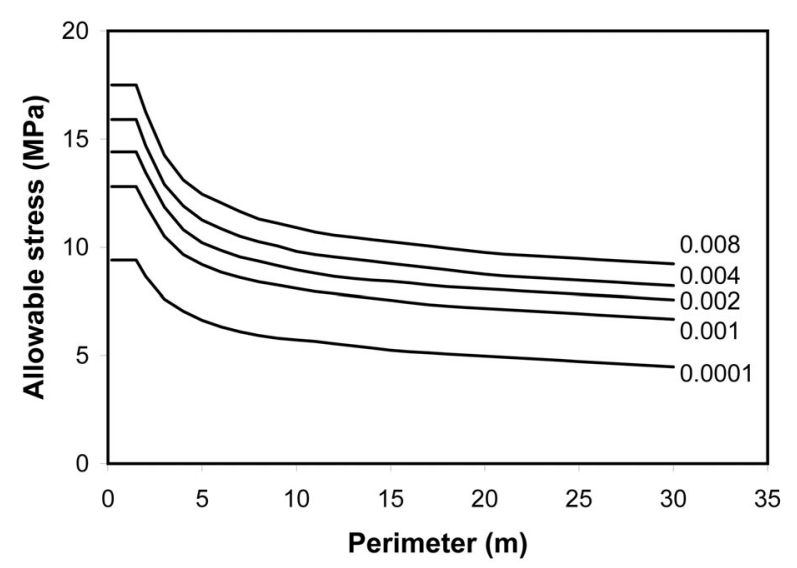

Fig. 5. Probability-of-breakage chart for window glass, redrawn from [6].

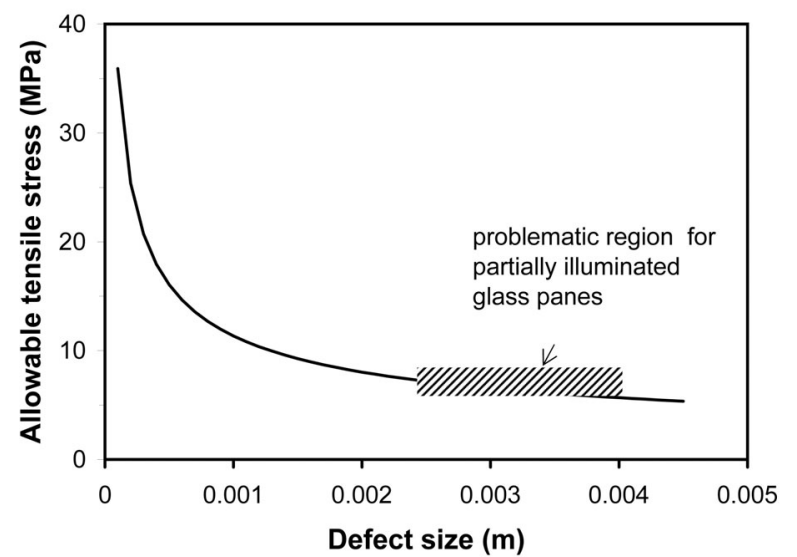

Fig. 6. Maximum allowable stress in window glass, as a function of crack size. 